\title{
Dependência da Importação de Insumos para a Defesa: Uma Breve Análise do Caso Colombiano
}

\section{The Defense Raw Materials Import Dependence: A Brief Analysis of the Colombian Case}

\section{DIEGO LOPES DA SILVA}

\section{INTRODUÇÃO}

Para além dos cálculos comerciais, como lucro e balança de pagamentos, a transferência de armamentos internacional possui uma dimensão geopolítica específica. Seu caráter político-estratégico, por vezes, chega a sobrepor suas vantagens econômicas. Se, por um lado, sua dimensão comercial pode implicar no aumento do ingresso de divisas, manutenção ou aumento da escala produtiva e/ou elevação na arrecadação de tributos, por outro, seu aspecto político traduz-se na possibilidade de alterar a balança de poder de uma determinada região, estabelecer embargos, garantir o status quo, ou influenciar conflitos internos de outros países sem precisar envolver-se diretamente. Sobre essa ambivalência, Fracalossi de Moraes (2012, 7) comenta que

Sob o ponto de vista político, os governos podem utilizar o fornecimento de armas como instrumento de política externa, ampliando ou reduzindo o poder relativo de outros Estados ou movimentos insurgentes. Podem, assim, fortalecer aliados, influenciar equilíbrios regionais de poder ou o curso de uma guerra. $\mathrm{O}$ apoio aos aliados pode também contribuir para o fortalecimento de uma aliança pois aumenta a confiança mútua e padroniza equipamentos, o que amplia a interoperabilidade entre as forças armadas de diferentes países. É possível, ainda, aumentar a influência sobre as políticas interna e/ou externa do receptor e, por fim, o fornecimento de armas pode ser uma forma de "selar" alianças entre Estados.

Diego Lopes da Silva - Doutorando em Relações Internacionais pelo PPGRI San Tiago Dantas (UNESP-UNICAMP-PUC \SP). Professor da Fundação Armando Alvares Penteado. E-mail: diego. lopes.silva@outlook.com. 
T. Wheelock (1978) define o exercício desse tipo particular de influência como a "manipulação do relacionamento de transferência de armamentos com o intuito de coagir o Estado recipiente a adequar sua política e suas ações aos desejos do Estado fornecedor" (Wheelock 1978, 123). Na operação, complementa John Sislin, o Estado recipiente possui um comportamento indesejado pelo Estado fornecedor, que por sua vez utiliza sua posição privilegiada para formatar as preferências do Estado recipiente (Sislin 1994, 667).

A reação do recipiente à tentativa de influência é condicional; o cumprimento ou não cumprimento [do desejo do fornecedor] é determinado pela natureza da tentativa e pela subsequente comparação dos custos e benefícios dos dois cursos de ação do receptor: continuar no mesmo curso ou alterar sua política por conta da tentativa de influência (Sislin 1994, 668).

A utilização da transferência de armamentos como ferramenta política foi usada em larga medida pelos Estados Unidos desde o fim da II Guerra Mundial, como meio de conter a expansão da influência soviética pelo globo e propagar a sua. Stephen Kaplan comenta a estratégia quando aplicada às Américas:

Em especial, eles buscaram enviar o excedente de armamentos norte-americanos à área, para se anteciparem à possibilidade de que nações fora do hemisfério obtivessem novamente influência militar na região; padronizar os armamentos das Forças Armadas latino-americanas; e prepará-las para missões de segurança interna, patrulha costeira, transporte e proteção de rotas marítimas (Kaplan 1975, 408).

Na Europa, os EUA instituíram em 1949 o Mutual Defense Assintance Act (MDAA), garantindo assistência militar aos países da região, concomitantemente à implementação do Plano Marshall (Fracalossi de Moraes 2011, 21). Outro programa utilizado em larga escala para o fornecimento de assistência militar aos países aliados foi o Mutual Assistance Pact (MAP's). Iniciados após a Guerra da Coreia, os MAP's garantiam aos EUA direito de trânsito, preferências comerciais em bens agrícolas e acesso a minerais estratégicos. Por sua vez, os países receptores receberiam como retorno treinamento militar dos norte-americanos, além de armamentos e equipamentos militares, quando não a preços baixos, gratuitamente. Apesar dos MAP's concentrarem-se na Europa e no Leste Asiático, diversos países latino-americanos foram incluídos no programa. Hal Klepak afirma que

Esses arranjos logo se tornaram o "recheio do sanduíche" do sistema interamericano de segurança, garantindo grande parte da coesão desfrutada, dado que o domínio norte-americano garantiu uma padronização dos armamentos, equipamentos, treinamento, doutrina, e modo 
de condução dos assuntos por, virtualmente, todo o hemisfério ao sul do Canadá. Ainda que os arranjos multilaterais continuassem a existir, seu papel pareceu frequentemente secundário quando comparado a esses lubrificantes que fizeram o sistema funcionar de fato (Klepak 2013, 53).

A União Soviética também desenvolveu políticas de contenção dessa natureza. Segundo Krause (1991), a quase total ausência de assistência econômica, de laços políticos, culturais, e sociais com os Estados recipientes, fez com que a URSS enfatizasse ainda mais o uso das transferências de armamentos para alcançar seus objetivos políticos. A competição geopolítica pela divisão dos mercados bélicos do Terceiro Mundo iniciou-se em 1955, com o fornecimento soviético de armamentos ao Oriente Médio. De acordo com Krause (1991), os casos mais bem documentados dizem respeito às tentativas norte-americanas de cooptar as elites latino-americanas. Como ilustração desse argumento e da competição pelos mercados de armamentos durante a Guerra Fria, Kaplan comenta a percepção norte-americana sobre a aproximação entre o Brasil e fornecedores europeus à época.

No entanto, o espectro do Brasil indo para a Europa e de um consequente afluxo de missões militares estrangeiras continuaram a ser uma grande preocupação para o Departamento de Defesa. Era esperado que tal rumo de acontecimentos diminuísse os laços entre as Forças Armadas do Brasil e dos Estados Unidos e um possível apoio brasileiro em diversas contingências. Em um futuro desconhecido, sentiu-se que a influência europeia ou qualquer influência militar que não fosse a norte-americana poderia ser prejudicial aos interesses dos EUA (Kaplan 1975, 421-422).

O mero fornecimento de armamentos, entretanto, não é condição suficiente para que se observe uma mudança no comportamento do receptor. Nesse sentido, a literatura especializada discute quais seriam as variáveis que determinam o sucesso no estabelecimento da influência e seu grau. Catrina (1998) enfatiza o nível de dependência das importações de armamentos de cada fornecedor em específico. Para o autor, o provedor é quem arca com os custos da transferência de armamentos. A dependência do receptor, por sua vez, é a "moeda” pela qual a relação é equacionada. Desse modo "as partes que têm mais benefícios do que custos em uma determinada relação, pagam o excedente por meio da dependência. E partes que têm mais custos são recompensadas pela dominância” (Catrina 1998, 149). A autonomia no estabelecimento das preferências converte-se, portanto, em um valor passível de troca.

Extrapolando os limites da abordagem de Catrina, Jan Oberg (1975) confere um contexto estrutural às transferências de armamentos. $\mathrm{O}$ autor 
analisa o fluxo bélico desde os países desenvolvidos em direção à periferia do sistema internacional, destacando o reduzido grupo de fornecedores majoritários e a larga quantidade de países receptores que se encontram em uma condição de dependência desses primeiros. A hipótese adotada pelo autor afirma que "o padrão das TA [transferências de armamentos] deve estar relacionada à estrutura global de domínio da sociedade internacional” (Oberg 1975, 214-215). A partir desse argumento, Oberg atesta que essa diferenciação estrutural é uma dimensão do imperialismo. De tal sorte, indicadores como investimentos estrangeiros, comércio internacional, desenvolvimento econômico e industrial relacionam-se ao padrão do fluxo internacional de armamentos.

Em uma interpelação complementar, porém com uma ênfase no papel das elites nacionais dos países receptores, Michael Barnett e Alexander Wendt (Barnett e Wendt 1993) tomam o problema da dependência militar no Terceiro Mundo desde a formação estatal. A constituição do Estado "refere-se à construção das instituições para controle territorial, e ao processo pelo qual uma determinada constelação de interesses da sociedade alcança o poder do Estado e o reconhecimento internacional ao invés de outra" (Barnett e Wendt 1993, 322). Partindo dessa definição, Barnett e Wendt argumentam que:

1) a dependência da economia internacional tende a criar regimes fracos aos quais as massas são uma ameaça a sua segurança ao invés de um recurso; 2) a dependência de assistência [externa] no campo da segurança em estruturas geopolíticas de impérios informais tende a criar elites cujas definições de segurança são aquelas de seus patronos, ao invés daquelas de suas massas; 3) a dependência da cultura militar global formata as ideias das elites sobre o que constitui Forças Armadas 'modernas' (Barnett e Wendt 1993, 322).

Os argumentos de Barnett e Wendt assemelham-se à perspectiva de Oberg na avaliação dos impactos da estrutura sobre o Terceiro Mundo e sua relação com componentes econômicos. Entretanto, diferentemente de Oberg, os autores evidenciam o papel das elites nacionais e sua associação aos patronos externos, estabelecendo assim uma relação de militarização ${ }^{1}$ dependente, que se manifesta desde a compra dos armamentos até a formulação conceitual da segurança nacional.

\section{IMPORTAÇÃO DE INSUMOS PARA A DEFESA NA AMÉRICA DO SUL: UMA BREVE ANÁLISE DA COLÔMBIA}

No último decênio, a América do Sul tornou-se um interessante mercado para os fornecedores de armamentos internacionais. Segundo o Sipri 
(Stockholm International Peace Research Institute), os gastos em defesa saltaram de US\$ 43,1 bilhões em 2000 para US\$ 67,7 bilhões em 2013 (Sipri, online). Países como Israel, Estados Unidos, Itália e Rússia buscaram expandir suas parcelas de mercado e atualmente figuram entre os principais fornecedores. Moscou aumentou expressivamente sua parcela no mercado sul-americano desde 2006, graças à parceria iniciada com a Venezuela a partir da venda de helicópteros de combate Mi-24VM/Hind-E, Mi-26/ Halo e Mi-8MT/Mi-17/Hip-H em 2005. Entretanto, ressaltamos que o aumento das vendas não é simplesmente uma função da renovação de seus aparatos bélicos defasados. Efetivamente, é uma consequência da baixa autonomia produtiva bélica dos países da sub-região. A capacidade de produção interna de armamentos, no melhor dos cenários, é incipiente. Há, contudo, casos que alcançaram sucesso nos anos 1980, como a Argentina, Brasil e Chile (Abetti e Maldifassi 1994). O Brasil, apesar do sucateamento da Base Industrial de Defesa no decorrer dos anos 1990, é o mais bem sucedido na América do Sul atualmente, contando com a Embraer no $66^{\circ}$ lugar na lista de maiores empresas bélicas do mundo (Sipri 2012, online).

A Venezuela, principal cliente russa na sub-região, aumentou sistematicamente suas compras desde 2005, alcançando um pico em 2008. Além de Caracas, a Rússia ainda tem como clientes na América do Sul a Argentina, Brasil, Colômbia, Equador, Peru e Uruguai. Porém, a soma de todos os armamentos vendidos a esses clientes entre 2004-2013 representa somente um pouco mais que $10 \%$ do total vendido à Venezuela no mesmo período, tal a importância de Caracas para os russos (Sipri, online). Do ponto de vista venezuelano, a importância de Moscou é ainda maior. Durante o mesmo período, as exportações russas de armamentos representaram 76,68\% de todas as transferências de armamentos feitas à Venezuela (Sipri, online). A expressividade da porcentagem sugere uma alta sensibilidade do sistema de defesa nacional venezuelano ao fornecimento russo. Ao lado da Venezuela, o Chile foi o país que mais importou armamentos entre 2004-2013. Não obstante, logrou manter certa diversidade entre seus fornecedores. ${ }^{2}$ Do total de armamentos transferidos ao país no período em questão, $15 \%$ vieram da Alemanha, 12\% da França, 16\% dos Estados Unidos, $11 \%$ do Reino Unido, 10\% da Espanha, e 24\% dos Países Baixos (Sipri, online).

Os Estados Unidos, históricos fornecedores de armamentos à América do Sul, manejaram para manter uma certa consistência no seu fornecimento em números absolutos. Não obstante, em números relativos, sua parcela diminuiu expressivamente. Em 2001, EUA e França praticamente dividiam o total das transferências de armamentos destinadas à América do Sul. Contudo, só contaram com 21,37\% do mercado em 2013. Apesar da diminuição, os EUA ainda mantêm clientes estáveis. Com o início do 
Plano Colômbia, Washington e Bogotá iniciaram uma série de programas de cooperação no combate ao narcotráfico. Entre 2009 e 2014, o maior beneficiário da ajuda militar externa norte-americana destinada à América do Sul foi a Colômbia, contando com mais de $75 \%$ da verba (Just The Facts, online). Como recipiente das exportações de armamentos, $43 \%$ de todas suas importações colombianas vieram de Washington (Sipri, online).

Dos países sul-americanos, o caso colombiano estimula maior interesse ao discutirmos a questão da dependência da importação de insumos para a defesa. Acompanhando uma tendência sub-regional, a Colômbia incrementou expressivamente seus gastos militares na última década. Em 2013, a cifra era de US $\$ 12$ bilhões, consideravelmente maior do que os US $\$ 7,8$ bilhões investidos em 2004. Do total sub-regional, Bogotá ocupa o segundo lugar na lista dos países que mais gastam com defesa, logo após o Brasil. O combate às Forças Revolucionárias da Colômbia (FARC) e a outros grupos insurgentes, como o Exército de Libertação Nacional (ELN), é a principal força propulsora dos investimentos em defesa.

Apesar dos gastos realizados, as cifras destinadas pelo Estado à contrainsurgência e ao combate ao crime organizado não são suficientes, compelindo Bogotá a buscar auxílio externo no tratamento de seu conflito doméstico. Em uma convergência de interesses com Washington, os países firmaram o Plano Colômbia no início dos anos 2000, que tinha como objetivo reduzir o cultivo, processamento, e distribuição de narcóticos. A partir de então, os EUA têm contribuído não só com cifras vultuosas, mas também com programas de treinamento militar no combate às forças ligadas ao narcotráfico.

$\mathrm{Na}$ esteira da ajuda econômica e militar provida pelos EUA, vêm as vendas de armamentos. Segundo Fracalossi de Moraes (2011, 19), o país percebe seu comércio bélico como uma ferramenta política, usando-o como forma de combater seus inimigos e grupos insurgentes sem se envolver diretamente no conflito. De fato, a Colômbia é altamente dependente da importação norte-americana de armamentos. Podemos atestar tal condição avaliando 1) as importações colombianas e 2 ) a indústria bélica doméstica.

Em relação às importações de sistemas de armas, os EUA permanecem como seu fornecedor predominante já há décadas. Do total importado entre 1950 e 2013, 47\% provém de Washington. Os outros parceiros são Espanha (4\%); Rússia (3\%), Israel (8\%), Alemanha (19\%), França (6\%) e Brasil (4\%) (Sipri, online). Na análise da produção bélica doméstica colombiana, utilizaremos o modelo proposto por Abetti e Maldifassi (1994). Segundo os autores, a performance da indústria de defesa nacional pode ser avaliada por alguns parâmetros, a saber: diversidade dos equipamentos produzidos; nível tecnológico incorporado; grau de absorção da produção 
interna pelas forças armadas nacionais; número de países clientes; nível tecnológico dos países clientes; e quantidade de vendas. Entretanto, tal é a debilidade da base industrial bélica da Colômbia que a aplicação do modelo de análise é parcial. A principal empresa bélica do país é a estatal Indústria Militar de Colombia (Indumil), especializada em armas leves, munições e explosivos, como o fuzil Galil e o lança-granadas MGL. A Cotecmar, por sua vez, tem sua produção voltada a embarcações de patrulha pequenas e médias, ao passo que a Corporación de la Industria Aeronáutica Colombiana S.A. (CIAC), também estatal, oferece aeronaves de treinamento. A produção doméstica tem baixa densidade tecnológica e elasticidade produtiva, ou seja, na eventualidade de um conflito de dimensões maiores, a indústria nacional não terá capacidade de produzir os bens necessários.

A participação ínfima no mercado internacional de armamentos como fornecedora é uma consequência do sucateamento da indústria nacional. Entre 1950 e 2013, a Colômbia só realizou uma única exportação, no ano de 2002. Bogotá vendeu ao México dois helicópteros Mi-8MT/Mi-17/ Hip-H de fabricação russa. Tomando por base a lista de equipamentos fornecida pela publicação Military Balance, é possível constatar a quase nula incorporação de materiais produzidos por indústrias colombianas pelas forças armadas nacionais. A aeronave de treinamento T34 Mentor, produzida pela CIAC, é uma das únicas absorções. Vemos, portanto, que a debilitada indústria bélica nacional colombiana, somada ao conflito interno contra as FARC, multiplica a já profunda dependência da importação de meios de defesa provisionada pelos EUA.

Há uma convergência notável entre a concepção de defesa colombiana àquelas pretendidas pelo governo dos Estados Unidos. Bogotá adota como objetivo estratégico

Llevar a un mínimo histórico la producción nacional de narcóticos, desarticular los grupos al margen de la ley y crear condiciones suficientes de seguridad para la consolidación (Colombia, 2011, online).

Não poderia ser de outro modo, visto que do contrário, os insumos não seriam concedidos. Contudo, ressaltamos o enrijecimento dos posicionamentos colombianos como uma consequência desse tipo específico de relacionamento. A manutenção das linhas de crédito e auxílio militar fornecidas pelos EUA, das quais o governo colombiano é dependente, apresenta-se como um forte incentivo à inflexibilidade da postura de Bogotá em eventuais negociações sobre visões conjuntas no âmbito do CDS. O atual estado de relacionamento dependente entre fornecedor e receptor contribui para a manutenção do status quo, visto que beneficia as preferências do fornecedor. Uma defecção entre as partes poderia representar um 
corte no fornecimento dos materiais necessários à manutenção da defesa do receptor. Tal condição dependente representa um sério obstáculo ao alcance de consensos no CDS. Recorremos uma vez mais a Barnett e Wendt (1993, 322), quando os autores afirmam que "a dependência de assistência [externa] no campo da segurança em estruturas geopolíticas de impérios informais tende a criar elites cujas definições de segurança são aquelas de seus patronos, ao invés daquelas de suas massas”.

\section{CONSIDERAÇÕES FINAIS}

Considerando a condição dependente de Bogotá desde as premissas de influência e dependência apresentadas, questionamo-nos sobre a relação entre sua posição estrutural no mercado internacional de armamentos e seu comportamento no âmbito do CDS. Apesar de ser um dos países com maior capacidade política e militar na sub-região, a Colômbia participa de maneira rarefeita no órgão. Desde 2008, conduziu apenas 8 atividades delegadas pelos Planos de Ação do CDS, ao passo que a Argentina coordenou 28. Desde o início do Conselho, a participação colombiana sempre foi titubeante, dadas as divergências sub-regionais na categorização das FARC. Sua principal antagonista é a Venezuela, que, por sua vez, apresentou reiteradas vezes demandas hostis à presença norte-americana na América do Sul. Juntamente com a Bolívia, Caracas rechaçou a proposta colombiana de inclusão no estatuto do CDS de um mecanismo que garantia o reconhecimento como forças de defesa nacional somente àquelas previstas pela Constituição.

Bogotá encontrou fora da sub-região um parceiro que lhe fornece o auxílio necessário no combate às FARC. Dada sua debilidade bélica, a parceria mostrou-se conveniente. Não obstante, é necessário que indaguemos quais são os efeitos políticos dessa associação para a América do Sul. A manutenção das linhas de auxílio norte-americanas à Colômbia constituem expressiva resistência para construção de concepções estratégicas comuns. O CDS delimita como um de seus objetivos sedimentar uma identidade estratégica sub-regional (Conselho de Defesa Sul-Americano, 2008, online). Porém, se partirmos das premissas expostas e discutidas pelo presente trabalho, a convergência submete-se à diminuição dos vínculos dependentes com os fornecedores bélicos. A reconfiguração do posicionamento dos países sul-americanos nos obriga a observar os investimentos realizados nas indústrias de defesa nacionais e na proliferação de atividades de produção conjuntas. No CDS, a questão da Indústria de Defesa tem sido preterida. Apenas $16 \%$ das atividades até o momento têm sido dedicadas a esse eixo. Predominantemente, os países dedicaram-se até o momento ao eixo políticas de defesa, que computa $41 \%$ de todas as atividades assumidas pelos 
países. A comparação ilustra, de forma clara, uma preferência dos países às atividades formuladoras de parâmetros normativos em detrimento de aspectos considerados mais pragmáticos, como a produção de sistemas de armas em conjunto.

Mais que conclusões sólidas, o presente artigo busca refazer perguntas desde a perspectiva da dependência da importação de insumos para a defesa. Ao ressaltarmos a precária autonomia de capacidade defensiva sul-americana, buscamos conferir contexto estrutural à cooperação em matéria de defesa na sub-região. Propomos, portanto, uma diferenciação - determinada pela estrutura - nas análises das dinâmicas de defesa e segurança dos países fornecedores e receptores, ou centrais e periféricos, como colocou Oberg. Resulta a nós pensar a cooperação em matéria de defesa desde a condição dependente.

\section{REFERÊNCIAS}

Abetti, P., Maldifassi, J. 1994. Defense industries in Latin American countries: Argentina, Brazil, and Chile. London: Praeger.

Andina. 2013. Primer avión militar diseñado por Unasur estará listo en el 2016. Lima. Disponível em: <http://www.andina.com.pe/Espanol/noticia-primer-avion-militar-disenado-unasur-estara-listo-el-20 16-458892.aspx\#.UfUjc9JkyWo $>$. Acesso em: 28 jan. 2015.

Bandeira, L. A. M. 2003. Brasil, Argentina e Estados Unidos: conflito e integração na América do Sul da Tríplice Aliança ao Mercosul. Rio de Janeiro: Revan.

Barnett, M., Wendt, A. 1993. "Dependent state formation and third world militarization”. Review of International Studies, 19: 321-347.

Brasil. Ministério da Defesa. 2008. Estratégia nacional de defesa. Paz e segurança para o Brasil. Disponível em: <http://www.planalto.gov.br/ccivil_03/_ ato2007-2010/2008/Decreto/D6703.htm>. Acesso em 28 jan. 2015.

Bueno, C., Cervo, A. 2008. História da política exterior do Brasil. Brasília: Ed. UnB.

Buzan, B. 1991. Introducción a los estúdios estratégicos. Madrid: Servicio de Publicaciones del E.M.E.

Carta Capital. 2014. EUA reativam IV Frota e preocupam dirigentes da AL. Disponível em: <http://www.cartamaior.com.br/?/Editoria/Internacional/ EUA-reativam-IV-Frota-e-preocupam-dirigentes-da-AL/6/14205>. Acesso em: 3 fev. 2014. 
Catrina, C. 1998. Arms tranfers and dependence. New York: Taylor \& Francis.

Chile. Ministerio de Defensa Nacional de Chile. 2009. El Consejo de Defensa Suramericano: crónicas de su gestación. Santiago de Chile. Disponível em: <http:// www.resdal.org/csd/gestacion-del-csd-libro-chile.pdf> Acesso em: 30 mar. 2015.

Conselho de Defesa Sul-Americano. 2008. Estatuto do Conselho de Defesa Sul-Americano, p. 3. Disponível em: <http://www.ceedcds.org.ar/ Portugues/o9-Downloads/PORT-ESTATUTO_CDS.pdf>. Acesso em: 15 mar. 2015.

2015. Planos de Ação. Disponível em:<http://www.ceedcds.org.ar/ Espanol/07-Consejo_Defensa_Suramericano/02_Plan_de\%20Accion.html>. Acesso em: 28 jan. 2015.

Eide, A., Thee, M. 1980. “Introduction”. In: Eide, A., Thee, M. Problems of contemporary Militarism. Croom Heim: London.

Emol. 2010. Ex Presidente de Costa Rica denuncia la "carrera armamentista" en América Latina. Disponível em: <http://www.emol.com/noticias/internacion$\mathrm{al} / 2010 / 05 / 21 / 414451 /$ ex-presidente-de-costa-rica-denuncia-la-carrera-armamentista-en-america-latina.html>. Acesso em: 11 dez. 2013.

Fracalossi de Moraes, R. 2011. O Mercado internacional de equipamentos militares: negócios e política externa. Texto para discussão 1596 IPEA. Brasília.

. 2012. A inserção externa da indústria brasileira de defesa: 1975-2010. Texto para discussão 1715 IPEA. Brasília. Disponível em: <repositorio.ipea.gov.br/ bitstream/11058/1241/1/TD_1715.pdf>. Acesso em: 15 mar. 2015.

Garay, C. 2012. "Las carreras armamentistas navales entre Argentina, Chile e Brasil (1891-1923)". História Crítica, 48, set./dez.

Glassman, J. 1975. Arms for the arabs. Baltimore: Johns Hopkins University Press.

Góis, C. 2009. "Chavez diz que 'ventos de guerra começam a soprar na América do Sul”. $O$ Globo, 10 ago. Disponível em <http://oglobo.globo. $\mathrm{com} / \mathrm{mundo} /$ chavez-diz-que-ventos-de-guerra-comecam-soprar-na-america-do-sul-3205425>. Acesso em 09 mar. 2015.

International Institute for Strategic Studies. 2014. The Military Balance. London: Routledge.

Just the Facts. 2015. U.S. Aid from International Narcotics Control and Law Enforcement, Entire Region, 2009-2014. Disponível em: <http://justf.org/ 
Program?program=International_Narcotics_Control_and_Law_Enforcement $>$. Acesso em: 17 fev. 2015.

Kaplan, S. 1975. "U.S. Arms Transfers to Latin America, 1945-1974: Rational Strategy, Bureaucratic Politics, and Executive Parameters”. International Studies Quarterly, 19, 4: 399-431, dec.

Kinsella, D. 1988. Arms transfer dependence and foreign policy conflict. Journal of Peace research, 35 (1), jan.

Klepak, H. 2013. The elusive common interests and objetives: the evolution of the inter-american security system. Calgary Papers in military and strategic studies, Occasional Paper 9: 43-66.

Krause, K. 1991. Military statecraft: power and influence in soviet and american arms tranfer relationships. International studies quaterly, 35 (3): 313-336, set.

Neuman, S. 1981. Arms transfers, indigenous defence production and dependency: the case of Iran. In: Amirsadeghi, H. (Ed.). The security of persian gulf. [s/l]: $[\mathrm{s} / \mathrm{n}], 131-150$.

. 1984. International stratification and third world military industries. International organization, 38 (1): 167-197.

Oberg, J. 1975. Arms trade with the third world as an aspect of imperialism. Journal of Peace research, 12 (3): 213-234.

Pajak, R. 1981. Soviet arms transfers as an instrument of influence. Survival, 23: 165-173.

Peru. 2005. Congreso de la Republica. Ley del sistema de seguridad y defensa nacional, n. 28.478, 23 mar. Disponível em: <http://www2.congreso.gob.pe/sicr/cendocbib/con4_uibd.nsf/303113E5BD816C37052579D40076D556/\$FILE/28478. pdf $>$. Acesso em: 28 jan. 2015.

Sipri. Arms transfers database. Disponível em: <http://www.sipri.org/databases/ armstransfers >. Acesso em: 12 mar. 2015.

The SIPRI Top 100 arms-producing and military services companies in the world excluding China. 2012. Disponível em: < http://www.sipri.org/research/armaments/production/Top100>. Acesso em: 02 mar. 2015.

Sislin, J. 1994. Arms as influence: the determinants of successful influence. The journal of conflict resolution, 38 (4), dez. 
Schmitt, C. 1992. O conceito do político. Petrópolis: Editora Vozes.

Tibilett, L. 2014. "Identidades estratégicas nos países da UNASUR e seu impacto na busca de uma identidade de defesa sul-americana. Rev. Bras. Est. Def., 1, 1, jul./ dez.

Vilela, F. de S. 2009. "Integração das indústrias de defesa na América do Sul. Revista da Escola de Guerra Naval, Rio de Janeiro, 14: 155-172.

Villa, R. 2008. "Corrida armamentista ou modernização de armamentos na América do Sul: estudo comparativo dos gastos militares”. Estudos e cenários, dez.

Villa, R., Viggiano, J. 2012. Trends in south americans weapons purchases at the beginning of the new millenium. Rev. Bras. Polit. Int., 55, 2: 28-47.

Wallerstein, I. 1996. The inter-state structure of the modern world-system. In: Smith, S., Booth, K., Zalewski, M. International theory: positivism and beyond. Cambridge: Cambridge University Press.

Wheelock, T. 1978. "Arms for Israel: the limit of leverage". International Security, 3,2 . 


\section{NOTAS}

1. Entretanto, é uma diversidade relativa, visto que os fornecedores em questão são todos membros da Otan (Organização do Tratado do Atlântico Norte).

2. Para Eide e Thee, a "militarização se manifesta no incremento dos armamentos, avanços na capacidade destrutiva dos armamentos, aumento no número de efetivos militares, crescimento dos gastos militares" (tradução nossa) (Eide e Thee 1980, 9). 


\section{RESUMO}

O objetivo do artigo é discutir quais as consequências da dependência da importação de insumos para a defesa na cooperação militar sul-americana. Partimos da premissa de que a dependência da importação de materiais bélicos subjuga o receptor à influência política de seus fornecedores. Concentramos nossa análise no caso colombiano.

Palavras-chave: Indústria de Defesa; Defesa; América do Sul; Conselho de Defesa Sul-Americano.

\section{ABSTRACT}

The aims of this article is to discuss the consequences of dependence on imports of raw materials for the defense in the South American military cooperation. We start from the premise that the dependence on imports of military material overwhelms the receiver to the political influence of its suppliers. We focus our analysis in the Colombian case.

Keywords: Defense Industry; Defense; South America; South American Defense Council. 